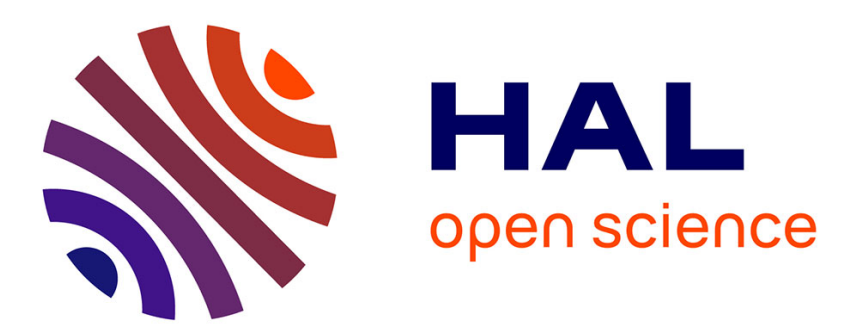

\title{
Behavior of Quenched and Tempered Steels under High Strain Rate Compression Loading
}

\author{
L. Meyer, K. Seifert, S. Abdel-Malek
}

\section{To cite this version:}

L. Meyer, K. Seifert, S. Abdel-Malek. Behavior of Quenched and Tempered Steels under High Strain Rate Compression Loading. Journal de Physique IV Proceedings, 1997, 07 (C3), pp.C3-571-C3-576. 10.1051/jp4:1997398 . jpa-00255555

\section{HAL Id: jpa-00255555 https://hal.science/jpa-00255555}

Submitted on 1 Jan 1997

HAL is a multi-disciplinary open access archive for the deposit and dissemination of scientific research documents, whether they are published or not. The documents may come from teaching and research institutions in France or abroad, or from public or private research centers.
L'archive ouverte pluridisciplinaire HAL, est destinée au dépôt et à la diffusion de documents scientifiques de niveau recherche, publiés ou non, émanant des établissements d'enseignement et de recherche français ou étrangers, des laboratoires publics ou privés. 


\title{
Behavior of Quenched and Tempered Steels under High Strain Rate Compression Loading
}

\author{
L.W. Meyer, K. Seifert and S. Abdel-Malek \\ TU Chemnitz-Zwichau, Lehrstuhl Werkstoffe des Maschinenbaus, 09107 Chemnitz, Germany
}

\begin{abstract}
Two quenched and tempered steels were tested under compression loading at strain rates of $\dot{\varepsilon}=2 * 10^{2} \mathrm{~s}^{-1}$ and $\dot{\varepsilon}=2 * 10^{3} \mathrm{~s}^{-1}$. By applying the thermal activation theory, the flow stress at very high strain rates of $10^{5}$ to $10^{6} \mathrm{~s}^{-1}$ is derived from low temperature and high strain rate tests.

Dynamic true stress - true strain behaviour presents, that stress increases with increasing strain until a maximum, then it decreases. Because of the adiabatic process under dynamic loading the maximum flow stress will occur at a lower strain if the strain rate is increased.

Considering strain rate, strain hardening, strain rate hardening and strain softening, a constitutive equation with different additive terms is successfully used to describe the behaviour of material under dynamic compression loading. Results are compared with other models of constitutive equations.
\end{abstract}

Résumé: Deux aciers de traitement thermique ont été testés en compression à des vitesses de déformation de $2 * 10^{2}=\mathrm{s}^{-1}$ et $10^{3}=\mathrm{s}^{-1}$. En appliquant la théorie de l'activation thermique la contrainte d'écoulement aux très grandes vitesses de déformation de $10^{3}$ à $10^{6} \mathrm{~s}^{-1}$ est déduite à partir des tests à faible température et vitesse élevée. Le comportement dynamique contrainte vraie - déformation vraie montre que la contrainte augmente avec la déformation jusqu'à un maximum puis décroît. En raison du processus adiabatique pour un chargement dynamique, la contrainte d'écoulement maximale apparaît pour une déformation plus faible lorsque la vitesse de déformation augmente. Une équation constitutive avec des termes additifs divers a été utilisée avec succès afin de décrire le comportement du matériau sous compression dynamique, tout en considérant la vitesse de déformation, l'écrouissage, la vitesse d'écrouissage et l'adoucissement. Les résultats sont comparés avec ceux d'autres modèles d'équations constitutives.

\section{Introduction}

Mechanical testing gives informations about material behaviour at different temperatures and strain rates. The results are needed for the numerical analysis and the simulation of high strain rate deformation processes such as automobile crash test or high speed metal forming processes. For these processes the range of relatively high strain and very high strain rate is of great interest.

For such simulation technique the true material behaviour under extreme deformation velocity is sought. This high deformation rate combined with precise stress measurement cannot be realized with today's experimental instruments. High dynamic tension and compression tests cannot be done beyond strain rates of $10^{3}$ to $10^{4} \mathrm{~s}^{-1}$.

Because of the necking instability under tension loading, stresses at high strains cannot be characterized. In the contrary, under compression loading the stress strain behaviour can be measured up to high deformation grade. In practice, too, many deformation processes occur under compression loading. 


\section{Estimation the flow stress at very high strain rates}

The influence of strain rate and test temperature on flow stress is caused often by thermally assisted interaction between mobile dislocations and short range obstacles[1]. The relation between strain rate and temperature is considered as an Arrhenius equation [2] as follow:

$$
\dot{\varepsilon}=\dot{\varepsilon}_{0} e^{\frac{-\Delta G}{k T}}
$$

where $\mathrm{k}$ is the Boltzmann constant; $\dot{\varepsilon}_{0}$ is the frequency factor, it consists of the Burgers vector, the mobile dislocation density, dislocation velocity, distance between obstacles and the Taylor factor. $\Delta \mathrm{G}$, the activated free enthalpy, depends on the difference between the applied stress and the athermal stress. $\Delta G$ has the value $\Delta G_{0}$ when the thermal activated stress equals zero.

For a given strain, the stress is the same for all temperatures and strain rate values as long as $\Delta \mathrm{G}$ is constant in the range of the strain rate $\dot{\varepsilon}$ between $\dot{\varepsilon}_{0} \exp \left(-\Delta \mathrm{G}_{0} / \mathrm{kT}\right)$ and $\dot{\varepsilon}_{0}$. The validity of this modell was proved by Krabiell [3] up to strain rates of $200 \mathrm{~s}^{-1}$ and by Meyer [4] up to strain rates of $3000 \mathrm{~s}^{-1}$. In the region of very high strain rates an additional amount of stress might be added to the athermal and the thermal activated stress. This can be explained as a damping effect due to the dislocation drag. Up to now dislocation drag in metallic materials at very high strain rates is mentioned theoretically. but there is no precise experimental proof that in the range of very high strain rates a considerable damping effect appears.

Estimations for the quantitative influence of dislocation drag lead to some hundreds of MPa for $\dot{\varepsilon}=10^{5} \mathrm{~s}^{-1}$ [1]. As long as no better information is available, it is proposed, to use the thermal activation influence as a lower boundary condition for the strain rate dependance and to keep in mind the small possibility of some enhancements due to dislocation drag.

\section{Constitutive equation}

Quasistatic testing is an isothermal process; because of the strain hardening, the flow stress increases with increasing strain. In the contrary, under dynamic loading, the heat loss is lower than the temperature rise by mechanical work. This is why temperature of the specimen rises during the test and flow stress at higher deformations decreases. After a certain strain, the softening will be stronger than strain hardening, so that the flow stress decreases with increasing strain.

The temperature in the specimen is a function of flow stress and strain; it can be calculated from the following equation:

$$
\Delta T=\frac{\eta}{\rho c_{p}} \int \sigma d \varphi
$$

where $\rho$ is the density, $\mathrm{c}_{\mathrm{p}}$ is the specific heat capacity and $\eta$ is a function of the strain rate $\mathrm{f}(\dot{\varepsilon})$; it is found [5] that $\eta=0.9$ at $\dot{\varepsilon}=200 \mathrm{~s}^{-1}$, taking $\eta=1$ at $\dot{\varepsilon}=\dot{\varepsilon}_{0}$ then $\eta$ could be calculated from $\eta=0.0093 \ln (\dot{\varepsilon})+0.85, \sigma$ is the true stress and $\varphi$ is true plastic strain. If all energy is converted into temperature increase with negligible heat loss, $\eta$ will be unity. In the higher strain rate tests the enhanced strength causes more energy absorption, which brings higher temperatures and shifts the maximum of the true compression stress - strain curve to lower strains with rising strain rates. These changes in stressstrain behaviour as a function of deformation and strain rate shall be represented in the constitutive equation. 
For the mathematical discription of the quasistatic stress strain behaviour the Ludwik-type [6] is often

$$
\text { used: } \quad \sigma=\mathrm{a}+\mathrm{c} \varphi^{\mathrm{n}}
$$

where $\mathrm{a}$ is the elastic limit, $\mathrm{c}$ is the flow stress $(\sigma-\mathrm{a})$ at the strain unity and $\mathrm{n}$ is the strain hardening coefficient. Taking the strain rate effect into consideration, equation (3) may be extended as follows:

$$
\sigma=\mathrm{a}+\mathrm{b} \log \dot{\varepsilon}+\mathrm{c} \varphi^{\mathrm{n} 1} \dot{\varepsilon}^{\mathrm{n} 2}
$$

This equation describes the strain hardening process only. Due to increasing temperature during the impact loading a softening term must be taken into consideration separated from the hardening part. Therefore a constitutive equation for describtion of material behaviour under dynamic compression loading can be written as

$$
\begin{aligned}
& \sigma=\mathrm{a}+\mathrm{b} \log \dot{\varepsilon}+\mathrm{c} \varphi^{\mathrm{n} 1} \dot{\varepsilon}^{\mathrm{n} 2}-\mathrm{d} \varphi^{\mathrm{m} 1} \dot{\varepsilon}^{\mathrm{m} 2} \\
& \text { in the limits } \quad \begin{array}{c}
0<\varphi<1 \\
10^{0}<\dot{\varepsilon}<10^{6} \mathrm{~s}^{-1}
\end{array}
\end{aligned}
$$

where $a, b, c, d:$ constants

$\mathrm{n} 1, \mathrm{n} 2 \quad$ : hardening exponents

$\mathrm{m} 1, \mathrm{~m} 2$ : softening exponents

\section{Experimental}

Dynamic compression tests were carried out with Hopkinson bar apparatus at room temperature and with drop weight tower at room and different low temperatures, to compare the results with those of quasistatic compression tests carried out on an universal test machine at room temperature. Cylindrical specimens, 6 $\mathrm{mm}$ in diameter and $6 \mathrm{~mm}$ in length, were used in all tests. The mechanical properties of the investigated materials under tensile loading are shown in table 1.

\begin{tabular}{|c|c|c|c|c|}
\hline Steel & $\begin{array}{c}\text { Hardness } \\
\text { HV30 }\end{array}$ & $\begin{array}{c}\text { Yield stress } \\
\sigma_{0.2}[\mathrm{MPa}]\end{array}$ & $\begin{array}{c}\text { Ultimate tensile strength } \\
\sigma_{\mathrm{m}}[\mathrm{MPa}]\end{array}$ & $\begin{array}{c}\text { Fracture strain } \\
\mathrm{A}_{5}[\%]\end{array}$ \\
\hline 30CrNiMo8 & 290 & 810 & 960 & 18.5 \\
\hline 25CrMo4 & 410 & 1290 & 1350 & 13.4 \\
\hline
\end{tabular}

Table 1: Mechanical properties of test materials

Two strain gages were glued on each specimen in order to get accurate measurements of strain and also of strain rate at beginning of deformation process. The plastic strain rate $\dot{\varepsilon}_{\mathrm{pl}}$ at $\varepsilon=2 \%$ is used in the following discussion.

\section{Results and discussion.}

Results of the compression tests show that yield stress increases with decreasing test temperature. The flow stress $\sigma_{\mathrm{p} 1}$ (flow stress at $1 \%$ plastic strain) of steel $30 \mathrm{CrNiMo} 8$ is measured to $930 \mathrm{MPa}$ at room temperature and strain rate $\dot{\varepsilon}$ of $200 \mathrm{~s}^{-1}$, at the low temperature of $77 \mathrm{~K}$ and the same strain rate, $\sigma_{\mathrm{pl}}$ increased to $1600 \mathrm{MPa}$. For steel $25 \mathrm{CrMo} 4, \sigma_{\mathrm{pl}}$ increases from $1450 \mathrm{MPa}$ to $2045 \mathrm{MPa}$ at the same conditions.

The activation energy $\Delta \mathrm{G}$ was calculated for each experiment using equation (1), the frequency factor $\dot{\varepsilon}_{0}$ was taken with $10^{7} \mathrm{~s}^{-1}$ for such type of steel [4]. Figure 1 shows the relation of flow stress to activation energy $\Delta \mathrm{G}$ in the range from room temperature and quasistatic loading, up to $77 \mathrm{~K}$ and high 
strain rate. This relationship means that all tests lie in the thermal activated region. The proof for the real equivalence of temperature and strain rate at the same values of activation enthalpy was given by Meyer and by Krabiell $[3,4,7]$ using low and high alloy steels. Therefore, the equivalent strain rate at room temperature can be calculated from the tests at low temperatures; an example of the results of this calculation is given in table 2 .

In figure 2 the flow stress is plotted at equivalent strain rate; the flow stress $\sigma_{\mathrm{pl}}$ rises continuously with increasing strain rate, and no sharp increase could be observed. As mentioned before, it is assumed now. that the influence of dislocation drag remains small up to $\dot{\varepsilon}=10^{5}-10^{6} \mathrm{~s}^{-1}$.

The thermal activation analysis can be applied for high strain, if the effect of adiabatic heating under dynamic loading is taken into account[7]. This conclusion leads to the assumption that flow stress at high strain and very high strain rates could be estimated from a test at low temperature and lower strain rate only for the case that the process is adiabatic. Therefore, low temperature tests were carried out at strain rates $\dot{\varepsilon}$ of nearly $200 \mathrm{~s}^{-1}$ on the drop weight tower.

\begin{tabular}{|c|c|c|c|}
\hline $\begin{array}{c}\text { kind of } \\
\text { compression test }\end{array}$ & $\begin{array}{c}\text { temperature } \\
{[\mathrm{K}]}\end{array}$ & $\begin{array}{c}\text { measured strain } \\
\text { rate }\left[\mathrm{s}^{-1}\right]\end{array}$ & $\begin{array}{c}\text { equivalent strain } \\
\text { rate at RT }\left[\mathrm{s}^{-1}\right]\end{array}$ \\
\hline quasistatic & 293 & 0.001 & 0.001 \\
\hline drop weight & 293 & 200 & $2.010^{2}$ \\
\hline drop weight & 213 & 200 & $3.8310^{3}$ \\
\hline drop weight & 173 & 200 & $1.6810^{4}$ \\
\hline drop weight & 77 & 200 & $5.8 \times 10^{5}$ \\
\hline hopkinson bar & 293 & 2000 & $2.010^{3}$ \\
\hline
\end{tabular}

Table 2: Average values of measured and calculated strain rates

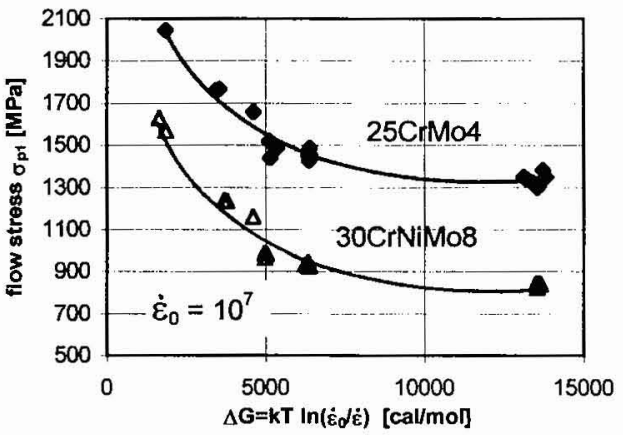

Fig. 1: Flow stress as a function of the activation enthalpy

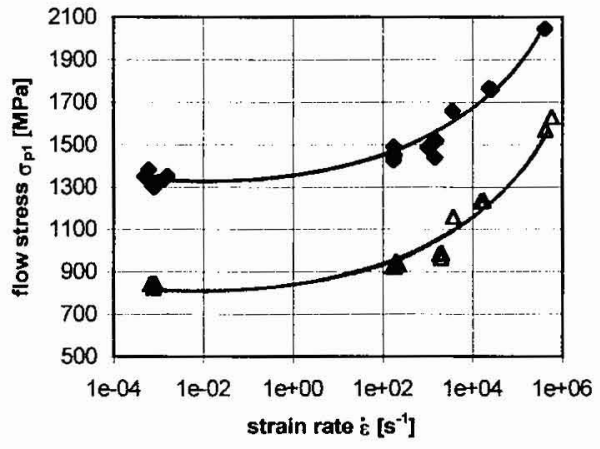

Fig. 2: Flow stress $\sigma_{p 1}$ versus equivalent strain rate

The true stress-true plastic strain data under dynamic loading for the investigated materials are shown in figures 3 and 4. At higher strain rates increasing flow stress values are found until true strains $\varphi$ of 0.1 to 0.3 . Till to strains of $\varphi=0.7$ friction effects are negligible. For strains $\varphi>0.7$ it is recommended to extrapolate the flow stress behaviour and not to take the experimentally measured values, which might be influenced by unknown friction effects. 
Many constitutive equations were developed to describe the behaviour of material under dynamic loading, some of these models describe only the behaviour of yield stress with strain rate changes, others describe strain and strain rate hardening effect without softening effect. A collection of these equations is discussed by Meyer[8]. Johnson et al.[9] proposed the following equation with a term for temperature softening,

$$
\sigma=\left(\sigma_{0}+\mathrm{B} \varphi^{\mathrm{n}}\right)(1+\ln \dot{\varepsilon})\left[1-\left(\mathrm{T}^{*}\right)^{\mathrm{m}}\right]
$$

$$
\text { with } T^{*}=\left(T-T_{r}\right) /\left(T_{m}-T_{r}\right)
$$

This equation is used to fit the data of experimental results, where $\mathrm{T}$ is the immediate absolute temperature of the deformed specimen. $T_{r}$ is the room temperature, $T_{m}$ is the melting point. $T^{*}$ could be written $(\Delta \mathrm{T} / 1500)$ calculating $\Delta \mathrm{T}$ from equation (2). A non linear regression program (SIGMA-PLOT) is used to fit the experimental data to eq. (5) and eq. (6). Figures 3 and 4 show a better agreement with the experimental data using eq. (5) in both steels. Although it has eight parameters, eq. (5) is easy to establish and also user friendly. Comparing the complicated method to determine the temperature at each flow stress with Johnson-Cook model and considering the better agreement at higher strains, eq. (5) is prefered.

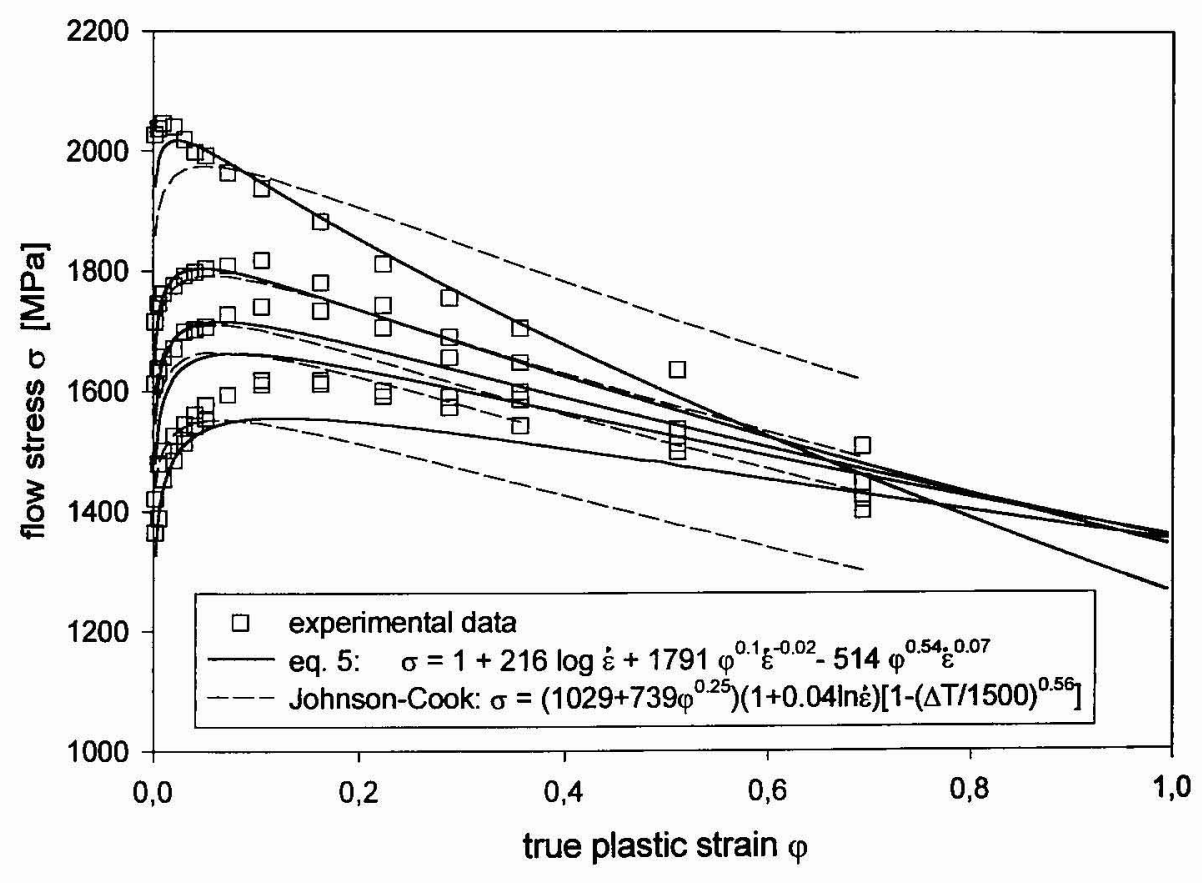

Fig. 3: Experimental data and constitutive equations for steel 25CrMo4 


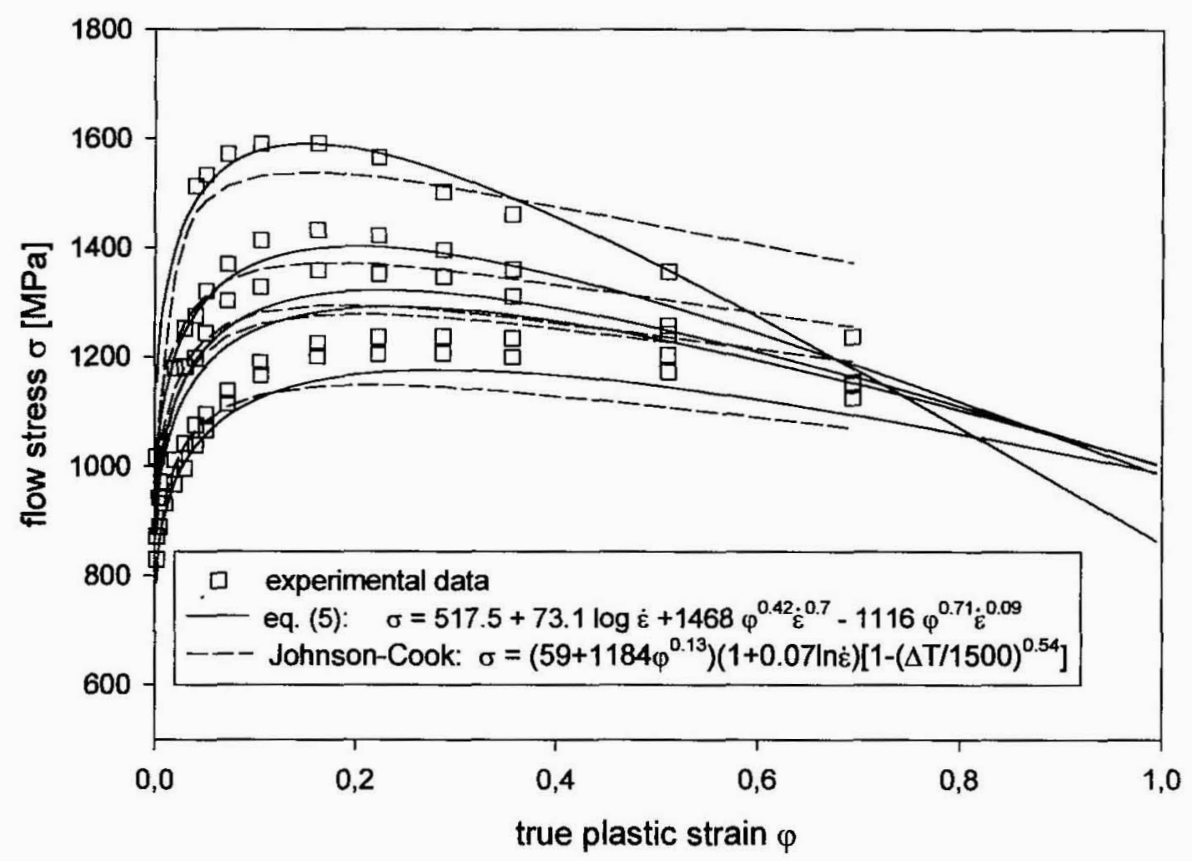

Fig. 4: Experimental results and constitutive equations for steel $30 \mathrm{CrNiM0} 8$

\section{Conclusions}

1. Material behaviour at very high strain rates on the Basis of a lower boundary condition could be estimated from low temperature testing, when the process is adiabatic

2. With a constitutive equation composed by terms, considering strain, strain rate hardening and softening, the material behaviour can be described more accurately.

\section{References}

[1] Vöhringer, O. in "Material behaviour at high rates"; Chiem, C. Laboratoire des science des materiaux de la mecanique ENSM, Nantes, 1990

[2] Zener, C. and Hollomon, J. J. appl. Phys. 15(1944) 22-32

[3] Krabiell, A. Ph. D Diss RWTH Aachen 1982, Germany

[4] Meyer, L. W. Ph. D Diss Dortmund 1982, Germany

[5] Hesse, W. Diss. Ph.D. RWTH Aachen 1986, Germany

[6] Ludwik, P. Phys. Z. 10: 411 (1909)

[7] Meyer, L. W. in: Inst. Phys. Conf. Ser. No. 70 (1984) 81-88

[8] Meyer, L. W. in:,Shock-wave and high strain rate phenomena in materials" edited by Meyers, M et al., Marcel Dekker, Inc. 1992, New York

[9] Johnson, G. R. and Cook, W. H., proc. $7^{\text {th }}$ Intern. Symp. Ballistics, am. Def. Prep. Org. (ADPA) Netherland, 1983 